\title{
Effects of food with two oral rehydration therapies: a randomised controlled clinical trial
}

\author{
N H Alam, T Ahmed, $M$ Khatun, A M Molla
}

\begin{abstract}
To evaluate the impact of food on the efficacy of oral rehydration solution (ORS), a randomised, controlled clinical trial was conducted in 182 adults with cholera. After initial rehydration with an intravenous polyelectrolyte solution for four hours, the patients were randomised to receive one of four rehydration therapies: glucose based ORS and no food for the first 24 hours (group A), glucose based ORS plus food from the beginning of treatment (group B), rice based ORS with no food for the first 24 hours (group C), and rice based ORS plus food from start of therapy (group D). Tetracycline was given after $\mathbf{7 2}$ hours to all patients. No significant differences in ORS intake, stool output, and duration of diarrhoea were noted between groups $A$ and $B$ and between groups $C$ and $D$. A substantial and significant reduction in stool output was, however, shown in the groups who received rice based ORS irrespective of feeding. These results show that food does not potentiate the efficacy of either glucose based or rice based ORS in adults with cholera. Rice based ORS compared with glucose ORS substantially reduces purging in cholera patients.
\end{abstract}

Rehydration therapy with the present glucose based oral rehydration solution recommended by the World Health Organisation (WHO-ORS) does not reduce the volume or frequency of stools. ${ }^{1-t}$ Since many water soluble organic molecules, including glucose, can enhance the absorption of sodium from the small intestine, ${ }^{5}$ it has been suggested that optimum exploitation of this phenomenon could lead to the development of an improved ORS formulation that would not only successfully replace the deficit of salts and water in diarrhoea but also actively induce absorption, with reduction of the stool volume and duration of diarrhoea. ${ }^{6}$ Based on this suggestion, cereal based ORS formulations have been shown to reduce stool volume, vomiting, and ORS consumption. ${ }^{-9}{ }^{-9}$ Rice powder is the usual constituent of these mixtures and contains complex carbohydrate and protein which, on digestion, should slowly liberate glucose, oligosaccharides, small peptides, and amino acids and accelerate salt and water absorption without any osmotic penalty. Starches and proteins in mixed diets (cereal, lentil, meat, and fish) release glucose, amino acids, and short chain peptides, all of which enhance absorption of sodium and water. Similarly, mixed food might be expected to convert a complete glucose electrolyte solution into an improved ORS.

In this study, we have examined the effect of giving a large conventional meal (usually eaten by Bangladeshi people) with ORS. In addition, we have compared rice containing ORS with glucose based ORS to determine which is better in the treatment of cholera patients.

\section{Patients and methods}

This study was carried out between July 1986 and December 1988. Adults (15 to 60 years) of either sex with a history of watery diarrhoea for 24 hours or less and with moderate or severe dehydration, presence of Vibrio cholerae in fresh stool specimen by dark field microscopic examination, and no history of antidiarrhoeal or antimicrobial drug consumption before admission were included in the study. Written informed consent was obtained from the patients or their legal guardians. The study was approved by the Ethical Review Committee of this institution.

At admission to hospital the body weight of each patient was determined and a thorough clinical examination was undertaken by one of the investigators. The dehydration status of the patients was assessed according to WHO guidelines. ${ }^{10}$ Patients with moderate dehydration had increased thirst, sunken eyes, lost skin turgor, and low volume peripheral pulses (estimated loss of body weight $(6-9 \%)$. Patients with severe dehydration had additional features of hypovolaemic shock such as cold, sweaty hands and feet, and very feeble or imperceptible peripheral pulses (estimated loss of body weight $\geqslant 10 \%$ ). All patients were given intravenous polyelectrolyte solution containing $\mathrm{Na}^{+}, 133 \mathrm{mmol} / \mathrm{l} ; \mathrm{Cl}^{-}, 98$ $\mathrm{mmol} / \mathrm{l} ; \mathrm{K}^{+}, 13 \mathrm{mmol} / \mathrm{l}$; and the equivalent of bicarbonate (in the form of acetate) $48 \mathrm{mmol} / \mathrm{l}$ for four hours to correct dehydration completely. The patients were then assigned to one of the following treatment regimens according to random numbers:

Group A - WHO-ORS. Food was withheld for the first 24 hours but was then offered. (The food offered to all groups was similar - boiled rice, bread, fish, chicken, egg, milk, and lentil); 
TABLE I Clinical characteristics and baseline information at admission of the four different treatment groups (values are mean $(S D)$ or number)

\begin{tabular}{|c|c|c|c|c|}
\hline & $\begin{array}{l}\text { Group A } \\
\text { WHO-ORS } \\
\text { without } \\
\text { food for } \\
24 h \\
(n=47)\end{array}$ & $\begin{array}{l}\text { Group B } \\
\text { WHO-ORS } \\
\text { and food } \\
\text { from start of } \\
\text { treatment } \\
(n=42)\end{array}$ & $\begin{array}{l}\text { Group C } \\
\text { Rice ORS } \\
\text { without } \\
\text { food for } \\
24 h \\
(n=46)\end{array}$ & $\begin{array}{l}\text { Goup D } \\
\text { Rice ORS } \\
\text { and food } \\
\text { from start of } \\
\text { treatment } \\
(n=47)\end{array}$ \\
\hline $\begin{array}{l}\text { Age (yrs) } \\
\text { Sex }(M / F) \\
\text { Admission body weight }(\mathbf{k g})\end{array}$ & $\begin{array}{l}26 \cdot 3(8 \cdot 5) \\
24 / 23 \\
39 \cdot 4(5 \cdot 6)\end{array}$ & $\begin{array}{l}28 \cdot 3(9 \cdot 1) \\
26 / 16 \\
39 \cdot 7(5 \cdot 1)\end{array}$ & $\begin{array}{l}28 \cdot 7(9 \cdot 9) \\
22 / 24 \\
38 \cdot 6(5 \cdot 9)\end{array}$ & $\begin{array}{l}30 \cdot 2(10 \cdot 6) \\
31 / 16 \\
40 \cdot 0(4 \cdot 9)\end{array}$ \\
\hline $\begin{array}{l}\text { Body weight after } 4 \mathrm{~h} \text { (baseline) } \\
\text { iv rehydration }\end{array}$ & $44 \cdot 0(6 \cdot 2)$ & $44 \cdot 5(5 \cdot 0)$ & $43 \cdot 3(5 \cdot 9)$ & $44 \cdot 9(5 \cdot 5)$ \\
\hline $\begin{array}{l}\text { Duration of diarrhoea before } \\
\text { admission (h) } \\
\text { No with severe/moderate }\end{array}$ & $10 \cdot 4(4 \cdot 9)$ & $11 \cdot 1(5 \cdot 5)$ & $10 \cdot 9(5 \cdot 2)$ & $11 \cdot 8(6 \cdot 4)$ \\
\hline $\begin{array}{l}\text { dehydration on admission } \\
\text { Baseline stool volume }(\mathrm{ml} / \mathrm{kg} / 4 \mathrm{~h}) \\
\text { Baseline iv fluid }(\mathrm{ml} / \mathrm{kg} / 4 \mathrm{~h}) \\
\text { Types of Vibrio cholerae isolated: }\end{array}$ & $\begin{array}{l}47 / 0 \\
36 \cdot 6(32 \cdot 6) \\
164 \cdot 4(39 \cdot 5)\end{array}$ & $\begin{array}{l}42 / 0 \\
44 \cdot 2(37 \cdot 5) \\
174 \cdot 9(43 \cdot 7)\end{array}$ & $\begin{array}{l}45 / 1 \\
36 \cdot 5(28 \cdot 8) \\
170 \cdot 9(36 \cdot 3)\end{array}$ & $\begin{array}{l}46 / 1 \\
35 \cdot 2(28 \cdot 8) \\
162 \cdot 5(36 \cdot 7)\end{array}$ \\
\hline $\begin{array}{l}\text { Classical } \\
\text { Eltor }\end{array}$ & $\begin{array}{l}18 \\
29\end{array}$ & $\begin{array}{l}20 \\
22\end{array}$ & $\begin{array}{l}21 \\
25\end{array}$ & $\begin{array}{l}25 \\
22\end{array}$ \\
\hline
\end{tabular}

Group B - WHO-ORS and food (as above) from the beginning of ORS therapy;

Group C - rice based ORS and no food for the first 24 hours;

Group D - rice based ORS and food from the beginning of ORS therapy.

The patients drank ORS freely and were also allowed plain water. Patients were given three meals daily: breakfast (bread, milk, egg, and sugar) at $7.00 \mathrm{am}$, lunch (boiled rice, fish/meat, lentil) at 12.00 noon, and supper (food as in lunch) at $7.00 \mathrm{pm}$, following the usual custom. All items of food were weighed before serving and the weight of left over food was subtracted from that offered to determine the amount the patient had consumed. The caloric value was calculated from the known values of the offered food estimated by adiabetic bomb calorimeter. Careful records of intake of ORS and plain water and the output of stool, urine, and vomit were kept and summarised at eight hourly intervals until the diarrhoea stopped. The end of diarrhoea was indicated by the passage of the first soft stool and/or no stool for 16 hours. Body weight was determined at admission, four hours after initial rehydration, and then every eight hours until the patient was discharged. The duration of diarrhoea was defined as the duration in hours from the time of admission to the passage of the last loose or watery stool. If a patient failed to maintain hydration with ORS because of extreme purging and excessive vomiting and developed moderate or severe dehydration at any time between the beginning of the study and the end of diarrhoea, intravenous fluid was given rapidly to correct dehydration and then the patient was given the assigned ORS. These events are referred to as unscheduled intravenous fluid therapy. Data from these patients were also included in the analysis. Tetracycline was given orally after 72 hours to all patients at a dose of $500 \mathrm{mg}$ six hourly for two days.

Stool specimens for culture of Vibrio cholerae, Salmonellae, and Shigellae and for microscopic examination to identify intestinal parasites were taken on hospital admission. Haematocrit, serum specific gravity, and serum concentrations of sodium, potassium, chloride, and bicarbonate on admission, at four hours, and at 24 hours after initial rehydration were measured.

Clinical characteristics such as age, sex, and body weight on admission, duration of diarrhoea before admission, amount of intravenous fluid given, and baseline purging rates were compared between the groups. Major outcome variables such as stool output $(\mathrm{ml} / \mathrm{kg})$, intake of ORS $(\mathrm{ml} / \mathrm{kg})$, and duration of diarrhoea (hours) were compared between the groups (group $\mathrm{A} v$ group $B$, group $C v$ group $D$, group $A v$ group $C$, and group $\mathrm{B} v$ group $\mathrm{D})$ using Student's $t$ test. The $\chi^{2}$ test was used for dichotomous variables - for example the number of patients who received unscheduled intravenous fluid and number of patients who vomited during the study period. Factorial analysis was also carried out using analysis of variance to evaluate ORS type and feeding status during first 24 hours and interaction between them on first 24 hours' stool output. Data were analysed in microcomputer using data analysis package (SPSS/PC+ Inc, USA).

\section{Results}

Of 182 patients studied, 47 in group A received WHO-ORS without food for 24 hours; 42 in group B received WHO-ORS and food from the start of ORS therapy; 46 in group $C$ received rice based ORS and no food for 24 hours; and 47 in group D received rice based ORS and food from the start of treatment. The clinical characteristics on admission and baseline information in the four different treatment groups were comparable (Table I). Data after feeding are shown in Table II. As expected, marked reductions in both stool output and ORS requirement were observed in the groups treated with rice ORS compared with the corresponding groups treated with glucose ORS $(\mathrm{p}<0.05)$. However, no significant differences were noted for stool output and ORS intake in the first 24 hours between fed and starved groups treated with either WHO-ORS or with rice ORS. In group A (WHO-ORS and starved for 24 hours), the water intake was reduced and urine output 
increased significantly in the first 24 hours compared with group B (WHO-ORS and fed from the start of therapy) where water intake was increased and urine output reduced.

Factorial analysis further confirmed that food had no effect in reducing stool volume during initial 24 hours $(F=0.43, p=0 \cdot 51)$ and the effect of rice ORS in reducing stool volume was highly significant $(\mathrm{F}=51 \cdot 0, \mathrm{p}<0 \cdot 001)$. This analysis also showed that there was no interaction between ORS type and feeding status during first 24 hours $(F=0 \cdot 22, p=0 \cdot 64)$.

Duration of diarrhoea was similar in all groups. Calorie intake from food during the first 24 hours in group B and group D was not statically different. The number of patients who received unscheduled intravenous fluid and the number of patients who vomited during the study period in all groups were also not significantly different. On admission, at four hours, and at 24 hours after ORS therapy the values of serum specific gravity, haematocrit, sodium, potassium, chloride, and total carbon dioxide were comparable in all treatment groups.

\section{Discussion}

In recent years, continued feeding during diarrhoea, in addition to oral rehydration therapy, has become well accepted as preventing malnutrition. However, very few studies have evaluated the role of giving food with ORS on clinical outcome during the treatment of acute diarrhoea. We hypothesised that eating a normal diet along with ORS may provide more substrates and help in better absorption of salt and water from the intestine and influence the clinical recovery of patients.

Our study shows that ORS plus food during the early part of the illness had no added advantage in reducing stool volume, vomiting, and duration of diarrhoea. Why food failed to produce any positive impact on the efficacy of ORS cannot be explained by this study. It may be assumed that glucose based ORS associated with food might have caused osmotic diarrhoea. Secondly, rice based ORS could have exerted the maximum effect on salt and water absorption leaving no room for an added effect of food. Similar findings were demonstrated in an earlier study in which WHO-ORS plus boiled rice in the early part of diarrhoeal illness was no better than WHO-ORS alone in the treatment of children with cholera." A previous study has reported a significant reduction in stool volume in cholera patients treated with rice based compared with glucose based ORS during the first 24 hour period when food was withheld. But the difference disappeared when food was introduced after 24 hours. ${ }^{12}$ It raises a question whether the early introduction of food could have shown the same beneficial effect. However, another study has shown that the addition of food to glucose based ORS was associated with an approximately $42 \%$ reduction in stool volume and the duration of diarrhoea. ${ }^{13}$ In this study, infants in the starved group drank substantially more glucose ORS in place of food and this could have contributed to osmotic diarrhoea. Also, the subjects were infants suffering from non-cholera diarrhoea, whereas in our study the subjects were adult cholera patients. It is expected that cholera patients suffer from severe diarrhoea with a high purging rate compared with noncholera patients. The severity of the illness in our patients was also reflected by the failure of more patients to maintain hydration with ORS and the prolonged duration of diarrhoea compared with patients in previous reports. ${ }^{1+15}$ Moreover, an antibiotic was given after 72 hours in our study, whereas it was used within or after 24 hours in the studies referred to above.

The reduction in stool seen in both groups of patients receiving rice based ORS with or without food in our study agrees with the previous reports. ${ }^{7-9}$ In addition, our results suggest that food did not potentiate the efficacy of either glucose or rice based ORS in the treatment of adult cholera patients.

This study was supported by grants from the UNICEF and the International Centre for Diarrhoeal Disease Research, Bangladesh (ICDDR,B). ICDDR,B is supported by countries and agencies which share its concern about the impact of diarrhoeal diseases on the developing world. Current donors include: The aid on the developing world. Current donors include: The aid agencies of the Governments of Australia, Bangladesh, Belgium,
Canada, Denmark, France, Japan, the Netherlands, Norway, Sweden, Switzerland, the United Kingdom and the United States; international organisations including the United Nations Capital international organisations including the United Nations Capital Development Fund, the United Nations Development Programme, the United Nations Children's Fund and the World Health Organisation; and private foundation

Foundation and the Sasakawa Foundation. We are grateful to Dr D Mahalanabis for his guidance in statistical analyses and writing of the manuscript. We thank Professor J R Hamilton for critical review of the manuscript. We would also like to thank the staff of the study ward of the clinical research centre for their service in patient care and Mr Meer Md
Ramzan Ali for secretarial work.

1 Pierce NF, Banwell JG, Mitra RC, et al. Effect of intragastric glucose-electrolyte infusion upon water and electrolyte balance in Asiatic cholera. Gastroenterology 1968; 55: 33343.

2 Hirschhorn N, Kinzie JL, Sachar DB, et al. Decrease in net stool output in cholera during intestinal perfusion with stool output in cholera during intestinal perfusion with
glucose containing solutions. NEnglf Med 1968; 279: 176glucose.

3 Mahalanabis D, Sack RB, Jacobs B, Mondal A, Thomas J. Use of an oral glucose electrolyte solution in the treatment of pediatric cholera: a controlled study. F Trop Pediatr Environ Child Health 1974; 20: 82-7.

4 Sack DA, Chowdhury AMAK, Eusof A, et al. Oral hydration in rotavirus diarrhoea: a double-blind comparison of sucrose with glucose electrolyte solution. Lancet 1978; ii: 280-3.

5 Schulz SG. Cellular models of sodium and chloride absorption by mammalian small and large intestine. In: Field $M$, Fordtran JS, Schultz SG, eds. Secretory diarrhea. Bethesda: American Physiological Society, 1980: 1-9.

6 Mahalanabis D, Patra FC. In search of a super oral rehydration solution: can optimum use of organic solute- mediated sodium absorption lead to the development of an absorption sodium absorption lead to the development of an absor

7 Molla AM, Nath SK, Molla A, Khatun M. Food-based oral rehydration salt solution for acute childhood diarrhoea. Lancet 1989; ii: 429-31.

8 Molla AM, Ahmed SM, Greenough WB, III. Rice-based oral rehydration solution decreases the stool volume in acute diarrhoea. Bull World Health Organ 1985; 63: 751-6.

9 Patra FC, Mahalanabis D, Jalan KN, Sen A, Banerjee P. Is oral rice electrolyte solution superior to glucose electrolyte solution in infantile diarrhoea? Arch Dis Child 1982; 57: $910-2$.

10 World Health Organisation. Programme for control of diarrhoeal diseases. A manual for the treatment of acute diarrhoea for use by physicians and other senior health workers. Geneva: WHO, physicians and other senior health workers.

11 Khin-Maung-U, Nyunt-Nyunt-Wai, Myo-khin, Mu-MuKhin, Tin-U, Thane-Toe. Effect of boiled-rice feeding in Khin, Tin-U, Thane-Toe. Effect of boiled-rice feeding in 1986; 40C: $249-54$.

12 Molla AM, Molla A, Rohde J, Greenough WB, III. Turning off the diarrhea: the role of food and ORS. $\mathcal{F}$ Pediatr Gastroenterol Nutr 1989; 8: 81-4.

13 Santosham M, Foster S, Reid R, et al. Role of soy-based, lactose-free formula during treatment of acute diarrhea. Pediatrics 1985; 76: 292-8.

14 Patra FC, Sack DA, Alam AN, Mazumder RN. Oral rehydration formula containing alanine and glucose for treatment of diarrhoea: a controlled trial. BMF 1989; 298: 1353-6.

15 Alam AN, Alam NH, Ahmed T, Sack DA. Randomised double blind trial of single dose doxycycline for treating cholera in adults. $B M \mathcal{F} 1990 ; 300$ : 1619-21. 